\title{
DISCUSSION
}

\section{A simplified working stress design method for reinforced soil walls}

\author{
M. EHRLICH*, S. H. MIRMORADI* and D. S. XU†
}

\section{Contribution by D. S. Xu}

The discusser thanks the authors for their effort in developing a simplified working stress design method for calculating the maximum reinforcement loads $\left(T_{\max }\right)$ in reinforced soil walls (Ehrlich \& Mirmoradi, 2016). The authors tried to simplify the EM method (Ehrlich \& Mitchell, 1994), which was further developed by Liu \& Won (2014), Liu (2015) and Liu $(2016 a, 2016 b)$ to take account of the non-constant Poisson ratio of soil and soil dilatancy. However, the proposed simplified working stress design method has some points that require further discussion or explanation, as presented in the following sections.

\section{Derivation of $\mathrm{K}_{c}$}

In the discussed paper, the derivation of $K_{\mathrm{c}}$ is the most important parameter to determine the maximum tensile forces mobilised in the reinforcement, $T_{\max }$; however, the derivation of $K_{\mathrm{c}}$ has some points that seem to be inappropriate.

(a) The expression $K_{\mathrm{c}}$ in equation (27) has a typographical error. It should be

$$
K_{\mathrm{c}}=\frac{K_{0}}{1+\left(1 / S_{\mathrm{i}}^{*}\right)} \quad \text { where } \quad S_{\mathrm{i}}^{*}=\frac{A_{\mathrm{r}} E_{\mathrm{r}}\left(1-v^{2}\right)}{A_{\mathrm{s}} E_{\mathrm{s}}}
$$

(b) The expression of the stress level (SL) given in the discussed paper contradicts the other equations (i.e. equations (27) and (29)) given by the authors.

(c) It seems that equation (29) in the discussed paper cannot be obtained based on the authors' derivations presented in the Appendix. According to the authors' derivation, the following expression is obtained

$$
\begin{aligned}
K_{\mathrm{c}}= & \frac{K_{0}}{1+\left\{A_{\mathrm{s}} E_{\mathrm{s}} /\left[\left(1-v^{2}\right) A_{\mathrm{r}} E_{\mathrm{r}}\right]\right\}} \\
& \text { where } K_{0}=\frac{v}{1-v}, K_{\mathrm{c}}=\frac{\sigma_{x}^{\prime}}{\sigma_{z}^{\prime}}
\end{aligned}
$$

Incorporating the expression of $E_{\mathrm{s}}, E_{\mathrm{s}}=$ $k P_{\mathrm{a}}\left(\sigma_{x}^{\prime} / P_{\mathrm{a}}\right)^{n} \mathrm{SL}$ and $\mathrm{SL}=8 K_{\mathrm{c}} \sin \left(\phi^{\prime} / 2\right)$, equation (42) can be rearranged as

$$
\begin{aligned}
& \text { Thus, } K_{\mathrm{c}} \text { is expressed as } \\
& K_{\mathrm{c}}=\frac{K_{0}}{1+\left\{\left[\left(\sigma_{x}^{\prime} / P_{\mathrm{a}}\right)^{n} \times 8 K_{\mathrm{c}} \sin \left(\phi^{\prime} / 2\right)\right] /\left[S_{\mathrm{i}}\left(1-v^{2}\right)\right]\right.}
\end{aligned}
$$

Figure 11 shows the comparisons of the derived $K_{\mathrm{c}}$ (i.e. equation (44)) with the original expression of $K_{\mathrm{c}}$ (i.e. equation (29) in the discussed paper) and the modified $K_{\mathrm{c}}$ (i.e. equation (31) in the discussed paper). The values of the derived $K_{\mathrm{c}}$ exhibit a large difference compared with the expression of $K_{\mathrm{c}}$ given by the authors. Fig. 12 shows how $K_{\mathrm{c}}$ varies with the stiffness index $S_{\mathrm{i}}$. The results show that $K_{\mathrm{c}}$ decreased with $S_{\mathrm{i}}$. However, when the $S_{\mathrm{i}}$ is close to 0 , this means that the backfill soil is not reinforced by the reinforcement, and thus the horizontal force is not in equilibrium and the backfill will collapse. The result of the derived $K_{\mathrm{c}}$ also proves this phenomenon, as it shows $K_{\mathrm{c}} \rightarrow 0$ when $S_{\mathrm{i}} \rightarrow 0$ (i.e. black line in Fig. 12).

Figure 13 shows the normalised reinforcement loads predicted with the above $K_{\mathrm{c}}$ expression and comparisons with the authors' proposed simplified method and Ehrlich \& Mitchell (1994). As shown in the figure, the derived normalised reinforcement loads based on the authors' simplified method diverge widely from the results of Ehrlich \& Mitchell (1994).

\section{The ultimate soil friction angle}

The authors gave two expressions of $\phi_{\text {ult }}^{\prime}$ in the discussed paper (i.e. equations (18) and (40) in the Appendix). It can be understood that the ultimate soil friction angle of equation (40) was derived based on the hyperbolic stressstrain model. However, the authors gave another expression of the ultimate soil friction angle (i.e. equation (18)) in the discussed paper. It seems the values of $\phi_{\text {ult }}^{\prime}$ in these two expressions are quite different when $R_{\mathrm{f}} \neq 1$, as shown in Fig. 14. As indicated in the figure, the values of $\phi_{\mathrm{ult}}^{\prime}$ are different for the different equations.

$$
\begin{aligned}
& K_{\mathrm{c}}=\frac{K_{0}}{1+\left\{\left[A_{\mathrm{s}} k P_{\mathrm{a}}\left(\sigma_{x}^{\prime} / P_{\mathrm{a}}\right)^{n} \times 8 K_{\mathrm{c}} \sin \left(\phi^{\prime} / 2\right)\right] /\left[\left(1-v^{2}\right) A_{\mathrm{r}} E_{\mathrm{r}}\right]\right\}}=\frac{K_{0}}{1+\left\{\left[\left(\sigma_{x}^{\prime} / P_{\mathrm{a}}\right)^{n} \times 8 K_{\mathrm{c}} \sin \left(\phi^{\prime} / 2\right)\right] /\left[S_{\mathrm{i}}\left(1-v^{2}\right)\right]\right\}} \\
& \quad \text { where } \quad S_{\mathrm{i}}=\frac{A_{\mathrm{r}} E_{\mathrm{r}}}{A_{\mathrm{s}} k P_{\mathrm{a}}}
\end{aligned}
$$

\footnotetext{
* Department of Civil Engineering, COPPE, Federal University of Rio de Janeiro, Rio de Janeiro, Brazil.

$\uparrow$ School of Civil Engineering and Mechanics, Huazhong University of Science and Technology, Wuhan, Hubei, P. R. China.
}

Equivalent at-rest $\mathrm{K}$ by considering facing inclination, $\mathrm{K}_{o w}$

The authors extended the proposed simplified method to calculate the $T_{\max }$ by considering the effect of facing inclinations. The expressions of $K_{\mathrm{c}}$ for vertical and 




Fig. 11. Comparison of $K_{\mathrm{c}}$ plotted against the effective friction angle $\left(v=0 \cdot 2, S_{\mathrm{i}}=0 \cdot 71\right)$

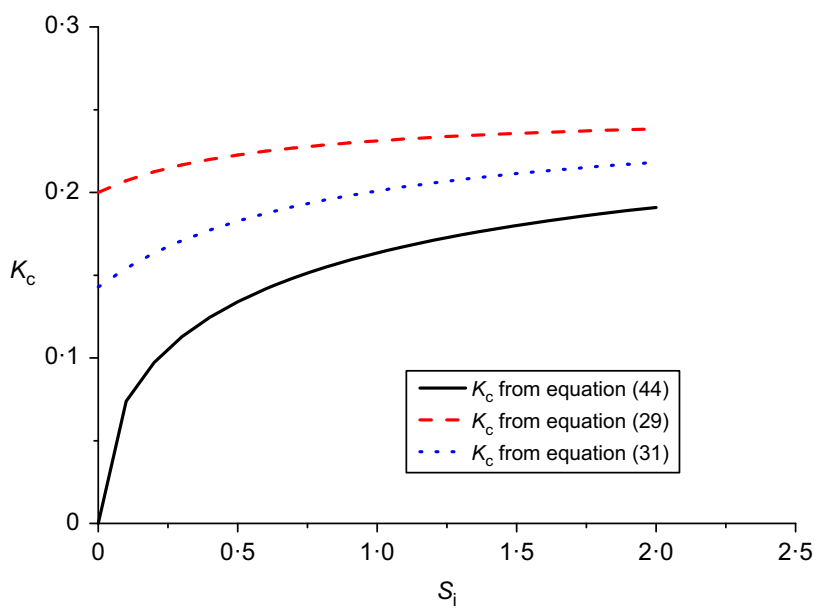

Fig. 12. Comparison of $K_{\mathrm{c}}$ plotted against $S_{\mathrm{i}}\left(v=0 \cdot 2, \phi^{\prime}=37^{\circ}\right)$

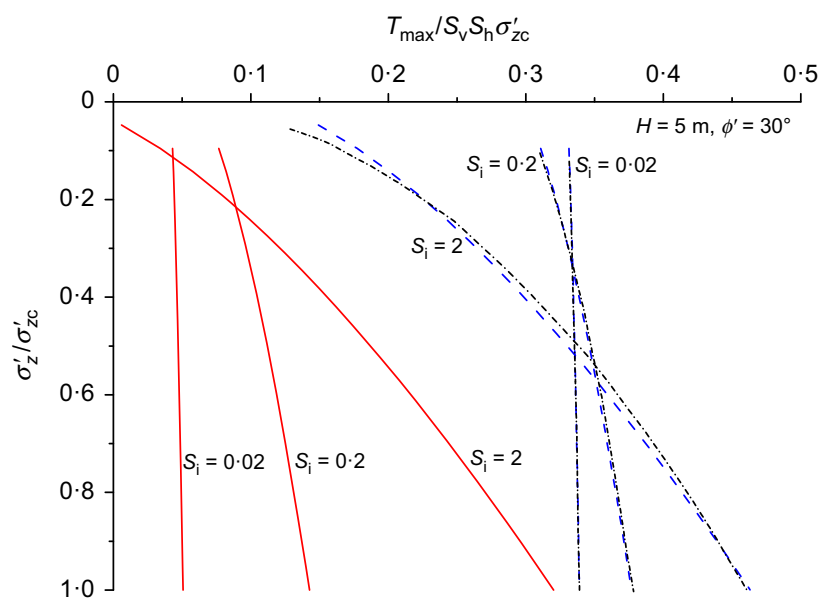

Fig. 13. Comparison of normalised reinforcement load for a $5 \mathrm{~m}$ high wall determined by the new derived formula in this discussion (solid lines), the formula provided in the discussed paper (dashed lines) and Ehrlich \& Mitchell (1994) (dash-dotted lines)

non-vertical walls are

$$
K_{\mathrm{c}}=\frac{\left[1+8 S_{\mathrm{i}}^{*} \sin \left(\phi_{\mathrm{ult}}^{\prime} / 2\right)\right] K_{0}}{2+8 S_{\mathrm{i}}^{*} \sin \left(\phi_{\mathrm{ult}}^{\prime} / 2\right)-K_{0}} \quad \text { for } \quad \omega<6^{\circ}
$$



Fig. 14. Comparisons of $\phi^{\prime}$ ult for $w=10^{\circ}, S_{\mathrm{i}}=2, R_{\mathrm{f}}=0 \cdot 7$

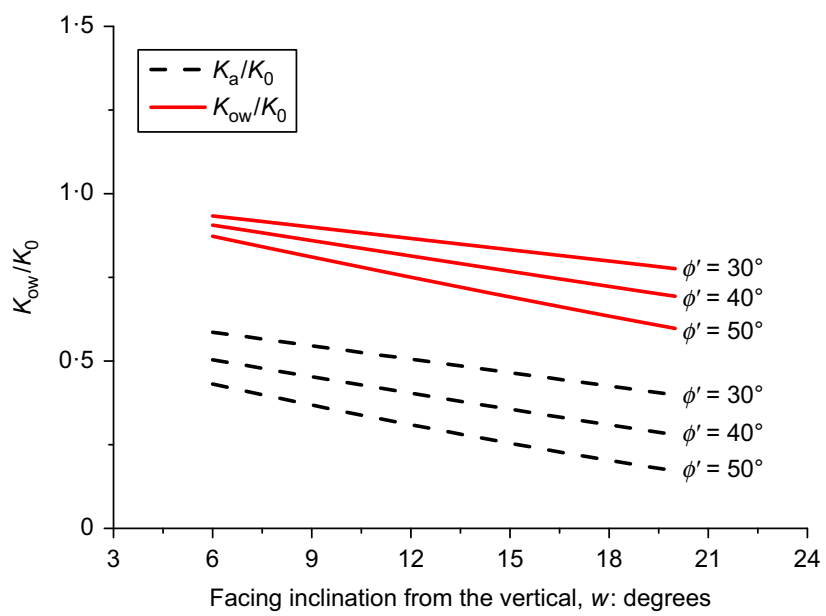

Fig. 15. Comparisons of the normalised $K_{\mathrm{ow}}$ and $K_{\mathrm{a}}$ for different facing inclinations

$$
K_{\mathrm{c}}=\frac{\left[1+8 S_{i}^{*} \sin \left(\phi_{\mathrm{ult}}^{\prime} / 2\right)\right] K_{\mathrm{ow}}}{2+8 S_{i}^{*} \sin \left(\phi_{\mathrm{ult}}^{\prime}\right)-K_{\mathrm{ow}}} \text { for } \omega>6^{\circ}
$$

For the inclined facing conditions, the horizontal equilibrium is different from the vertical wall. The $K_{\mathrm{r}}$ equation (i.e. equation (14)) presented in the discussed paper is different from that given in the Appendix (i.e. equation (35)).

Figure 15 shows the differences between $K_{\mathrm{ow}}, K_{\mathrm{a}}$ and $K_{0}$ for different wall inclinations. Comparisons are presented for three soil friction angles (i.e. $30^{\circ}, 40^{\circ}, 50^{\circ}$ ). The authors mentioned that the $K_{\mathrm{a}}$ was obtained based on the Coulomb earth pressure theory. Unfortunately, the $K_{\mathrm{a}}$ in the discussed paper did not take into account the friction between the backfill and the wall, whereas this friction is considered in the Coulomb theory and the American Association of State Highway and Transportation Officials (Aashto) method. Results of comparisons show that the values of the equivalent at-rest earth pressure coefficient $K_{\mathrm{ow}}$ are between the values of $K_{\mathrm{a}}$ and $K_{0}$.

\section{AUTHORS' REPLY}

The authors thank the discusser for his comments; the points he raises will be useful to readers. The points are mainly related to the derivation of the three parameters in the discussed paper: $K$ during compaction, $K_{\mathrm{c}}$; ultimate soil 
friction angle, $\phi_{\text {ult }}^{\prime}$; and equivalent at-rest $K$ considering facing inclination, $K_{\mathrm{ow}}$. Clarifications for these points are provided as follows.

\section{$\mathrm{K}_{c}$ evaluation}

As correctly mentioned by the discusser, equation (27) in the discussed paper has a typographical error. This equation should be expressed as

$$
K_{\mathrm{c}}=\frac{K_{0}}{1+\left(1 / \boldsymbol{S}_{\mathbf{i}}\right)}
$$

where

$$
\boldsymbol{S}_{\mathrm{i}}=\frac{A_{\mathrm{r}} E_{\mathrm{r}}\left(1-v^{2}\right)}{A_{\mathrm{s}} E_{\mathrm{s}}}
$$

$\boldsymbol{S}_{\mathbf{i}}$ is the relative soil-reinforcement stiffness index considering linear elastic behaviour for soil and reinforcement. To take into consideration the non-linearity of the soil behaviour, $E_{\mathrm{s}}$ can be expressed as

$$
\frac{E_{\mathrm{s}}}{1-v^{2}}=k P_{\mathrm{a}}\left(\frac{\sigma_{x}^{\prime}}{P_{\mathrm{a}}}\right)^{n} \mathrm{SL}
$$

The stress level, SL, decreases with soil strain and thus with $K_{\mathrm{c}}$. Assuming $\mathrm{SL}=K_{\mathrm{c}} / 8 \sin \left(\phi^{\prime} / 2\right)$, which was backcalculated to fit better with the original method, the parameter $\boldsymbol{S}_{\mathrm{i}}$ can be rearranged as follows (in the discussed paper, the SL equation has a typographical error)

$$
\boldsymbol{S}_{\mathrm{i}}=\frac{8 \sin \left(\phi^{\prime} / 2\right) S_{\mathrm{i}}^{*}}{K_{\mathrm{c}}}
$$

Thus

$$
K_{\mathrm{c}}=\frac{K_{0}}{1+\left[K_{\mathrm{c}} / 8 \sin \left(\phi^{\prime} / 2\right) S_{\mathrm{i}}^{*}\right]}
$$

Substitution of $K_{\mathrm{c}}=K_{0} /\left\{1+\left[1 / 8 \sin \left(\phi^{\prime} / 2\right) S_{\mathrm{i}}^{*}\right]\right\}$ into the equation above gives

$$
K_{\mathrm{c}}=\frac{K_{0}}{1+\left[\left(K_{0} /\left\{1+\left[1 / 8 \sin \left(\phi^{\prime} / 2\right) S_{\mathrm{i}}^{*}\right]\right\}\right) / 8 \sin \left(\phi^{\prime} / 2\right) S_{\mathrm{i}}^{*}\right]}
$$

Rearrangement of equation (51) gives equation (29) as presented in the discussed paper. As mentioned in the original paper under discussion, an adaptation is required for equation (29); for $S_{\mathrm{i}}=0$, a value of $K_{\mathrm{c}}=K_{\mathrm{a}}$ is required. Therefore, equation (29) is adapted as equation (31).

It should be noted that in the actual field conditions the wall may be far from failure and, in this condition, the determined $T_{\max }$ is higher than the corresponding Rankine $K_{\mathrm{a}}$ condition (see Fig. 16). In a specific layer, hypothetically, under zero horizontal strain, $\varepsilon$, the soil would be in the stress state corresponding to at-rest conditions and there would be no tension load in the reinforcements. With increasing horizontal strain, the horizontal soil stresses, $\sigma_{\mathrm{s}}$, decrease, approaching the active condition. Simultaneously, the reinforcement loads, $T_{\max }$, increase until equilibrium of the reinforced soil mass is reached. This equilibrium can be achieved with relatively small strains, and $T_{\max }$ under those conditions would be closer to the value corresponding to the at-rest condition, $K_{0}$, when the reinforcement is stiffer. When the reinforcement has lower stiffness, the strain required to reach equilibrium is higher and $T_{\max }$ approaches the value corresponding to the active condition, $K_{\mathrm{a}}$. This behaviour is controlled by the soil-reinforcement relative stiffness, $S_{\mathrm{i}}$, as defined by Ehrlich \& Mitchell (1994). Note that this simple

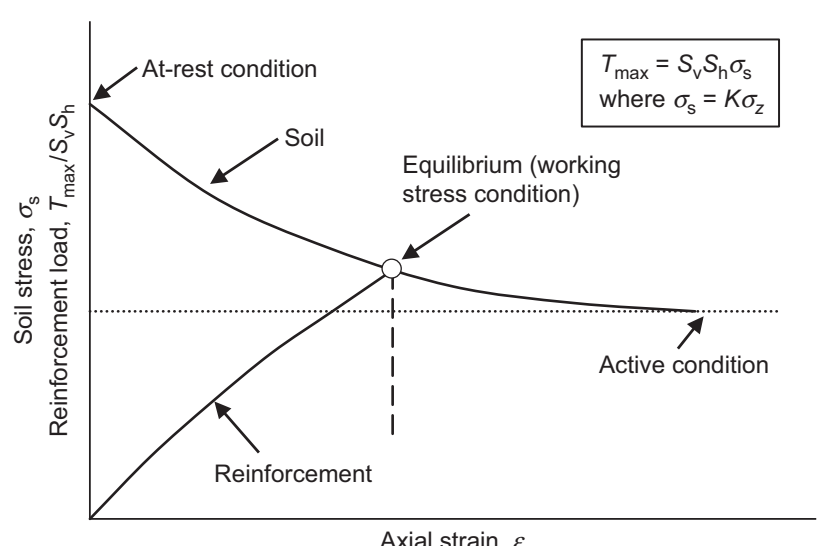

Fig. 16. Stress-strain compatibility between soil and reinforcement

model may represent the stress-strain behaviour of a reinforcement layer in a wall without the toe restraint condition. Nevertheless, if the combined effect of facing stiffness and toe restraint cannot be neglected, the reinforcement load may significantly reduce (Ehrlich \& Mirmoradi, 2013; Mirmoradi \& Ehrlich, 2015, 2016a, 2017; Mirmoradi et al., 2016).

\section{$\phi_{\text {ult }}^{\prime}$ evaluation}

As mentioned in the discussed paper, the ultimate soil friction angle of equation (40) was derived based on the hyperbolic stress-strain model. Then, based on this equation, equation (18) was derived to fit better the values calculated by the original EM method. As shown in Fig. 3 and Fig. 7 of the discussed paper, the results determined using the new proposed method agree well with those calculated by the original EM method and the numerical analysis considering different $R_{\mathrm{f}}$ values.

\section{$\mathrm{K}_{\text {ow }}$ evaluation}

The parameter $K_{\text {ow }}$ defined in the discussed paper is the equivalent at-rest earth-pressure coefficient that takes into consideration the effect of the facing inclination on the calculation (equation (20)). As stated in the discussed paper, equation (20) is a rearrangement of equation (32) as used by the Aashto simplified method. Note that for the calculation of $T_{\max }$ using the original EM method, the effective vertical stress is calculated using Meyerhof's (1955) method (equation (2)). As mentioned in the discussed paper, equation (2) was developed for a vertical wall. In the new proposed method based on the results of numerical studies, this equation is recommended to be used for $\omega<6^{\circ}(\omega$ is the facing inclination to the vertical). For $\omega>6^{\circ}$, the effective vertical stress can be calculated as $\sigma_{z}^{\prime}=\gamma^{\prime} z$.

In summary, the discussed paper proposed a simple working stress design procedure for the calculation of $T_{\max }$ that can explicitly take into account the effect of compaction-induced stress, reinforcement and soil stiffness properties, and facing inclination. A good agreement was observed between the new proposed method and data from physical and numerical model studies considering different wall heights, compaction efforts, facing inclinations, reinforcement stiffnesses and soil parameters. This method does not consider the effect of the soil dilatancy in its calculation. It should be noted that the dilatancy of soil may not significantly affect the reinforcement load in reinforced soil walls under working stress conditions (Mirmoradi \& Ehrlich, 2016b). 
Regarding the comment raised by the discussion contributor about the magnitude of $K_{\mathrm{c}}$ for $S_{\mathrm{i}}=0$, it should be noted that this hypothetical condition would lead to $K_{\mathrm{c}}=K_{\mathrm{a}}$, which is the limit equilibrium condition for a reinforced soil mass, as correctly considered by the proposed method.

\section{REFERENCES}

Ehrlich, M. \& Mirmoradi, S. H. (2013). Evaluation of the effects of facing stiffness and toe resistance on the behavior of GRS walls. Geotextiles Geomembranes 40, 28-36.

Ehrlich, M. \& Mirmoradi, S. H. (2016). A simplified working stress design method for reinforced soil walls. Géotechnique 66, No. 10, 854-863, http://dx.doi.org/10.1680/jgeot.16.P.010.

Ehrlich, M. \& Mitchell, J. K. (1994). Working stress design method for reinforced soil walls. J. Geotech. Engng, ASCE 120, No. 4, $625-645$.

Liu, H. B. (2015). Reinforcement load and compression of reinforced soil mass under surcharge loading. J. Geotech. Geoenviron. Engng, ASCE 141, No. 6, 04015017.

Liu, H. B. (2016a). Required reinforcement stiffness for vertical geosynthetic-reinforced-soil walls at strength limit state. Géotechnique 66, No. 5, 424-434, http://dx.doi.org/10.1680/ jgeot.15.P.208.

Liu, H. B. (2016b). Nonlinear elastic analysis of reinforcement loads for geosynthetic reinforced soil composites without facing restriction. J. Geotech. Geoenviron. Engng, ASCE 142, No. 6, 04016013.

Liu, H. B. \& Won, M. S. (2014). Stress-dilatancy and reinforcement load of vertical reinforced soil composite: an analytical method. J. Engng Mech., ASCE 140, No. 3, 630-639.

Meyerhof, G. G. (1955). The bearing capacity of foundations under eccentric and inclined loads. Proceedings of the 3rd international conference on soil mechanics and foundation engineering, Zurich, Switzerland, vol. I, pp. 440-445.

Mirmoradi, S. H. \& Ehrlich, M. (2015). Numerical evaluation of the behavior of GRS walls with segmental block facing under working stress conditions. J. Geotech. Geoenviron. Engng, ASCE 141, No. 3, 04014109.

Mirmoradi, S. H. \& Ehrlich, M. (2016a). Evaluation of the effect of Toe restraint on GRS walls. Transpn Geotech. 8, Special issue: Use of geosynthetics in transportation geotechnics, 35-44.

Mirmoradi, S. H. \& Ehrlich, M. (2016b). Closure to 'Numerical evaluation of the behavior of GRS walls with segmental block facing under working stress conditions'. J. Geotech. Geoenviron. Engng, ASCE 142, No. 4, 07016002.

Mirmoradi, S. H. \& Ehrlich, M. (2017). Effects of facing, reinforcement stiffness, toe resistance, and height on reinforced walls. Geotextiles Geomembranes 45, No. 1, 67-76.

Mirmoradi, S. H., Ehrlich, M. \& Dieguez, C. (2016). Evaluation of the combined effect of toe resistance and facing inclination on the behavior of GRS walls. Geotextiles Geomembranes 44, No. 3, 287-294. 